\title{
Analysis on the Application of Big Data Technology in "Internet + Wisdom Judicial Expertise"
}

\author{
Juan $\mathrm{Xu}^{1}$ \\ ${ }^{1}$ Sichuan Judicial and Police Officers Professional College, DeYang, Sichuan, China 618000
}

\begin{abstract}
It can be seen from the current development process of the field of forensic expertise that there are many problems in the application of the mechanism of the information structure. These problems lead to imperfect informatization construction process and too limited identification forms, which will have a great impact on the final identification results. This article summarizes the main content of big data technology in the construction of "Internet + Wisdom Judicial Expertise". This article discusses the specific application recommendations of big data technology in the "Internet + smart forensic appraisal", from focusing on forensic appraisal data collection and sorting, understanding forensic appraisal big data application requirements, building forensic appraisal big data analysis platform, and strengthening big data analysis platform resource network sharing four aspects.
\end{abstract}

\section{INTRODUCTION}

The continuous application of information technology has brought great changes to the development of various industries. Big data technology is not only a kind of information technology, but also a product of a specific stage. Compared with traditional information processing technology, big data has improved significantly in information processing range and information processing speed. At this stage, mankind has entered the era of big data development. We should build a corresponding data analysis platform to ensure that the platform can better complete the analysis tasks, which is also demonstrated in the judicial appraisal.

\section{The Necessity of the DeVelopment of "INTERNET + WISDOM JUDICIAL EXPERTISE"}

The development of network information technology has brought tremendous support to the progress of human society, and it has prompted people to enter the period of Internet development. At this stage, all industries who want to obtain more development opportunities need to establish a cooperative relationship with the network, and then regain a new life. In the judicial link, forensic appraisal is of great significance, and it needs to be integrated with Internet technology. The continuous improvement of China's judicial work has promoted many opportunities for progress in the judicial authentication industry. At present, in addition to the gradual increase in the number of judicial institutions in China, the number of cases involving judicial appraisal is also growing, thus creating favorable conditions for the development of
China's subsequent judicial undertakings. "Internet + Wisdom Forensic Expertise" is a new form of forensic identification in the entire Internet era. From the perspective of necessity, it mainly includes two aspects. First of all, it is one of the main means of self-development and self-improvement of judicial appraisal. In traditional work, the efficiency of forensic appraisal is limited and the cycle experienced is longer. With the help of Internet+, the efficiency of judicial appraisal will be rapidly improved, which can protect the legitimate rights and interests of applicants. At the same time, Internet + can further enhance the adaptability of judicial appraisal. Nowadays, the Internet has a very close relationship with people's lives, and the application rate of judicial appraisal is also extremely high. The previous physical evidence to the current electronic evidence are all included in the scope of judicial authentication. It can also be seen from this that "Internet + Wisdom Judicial Expertise" can greatly broaden the scope of judicial authentication, and its effect is becoming more and more obvious [1].

\section{Problems Existing in the CuRrent MANAGEMENT MODEL OF FORENSIC EXPERTISE}

\subsection{Forensic Authentication Management Standards Are not Uniform}

In terms of unified management, the main body of judicial authentication needs to be based on harmony and concentration, adopt a more scientific management method, integrate judicial authentication resources, and achieve overall planning. However, there is a 
phenomenon of multiple management among the current judicial appraisal management subjects, which are easy to do things independently, which affects the legitimacy and objectivity of judicial appraisal, and even destroys the appraisal result in serious cases. In addition, judicial appraisal does not have a unified standard for management subjects. Generally speaking, the main body of judicial appraisal management is the judicial administrative agency, which has no clear standards on the management authority and scope, which leads to the overlapping management problems between the judicial administrative department and the investigative agency in the judicial appraisal management. Its subject rights are not clearly defined. Each management department only makes management decisions based on its own interests. This not only makes the management system unable to be in a unified state, but also leads to the mixing of many poorly qualified appraisal agencies. Finally, the procedural characteristics in the judicial authentication process are not obvious, and there are no detailed regulations for judicial authentication. Especially in the aspects of appraisal procedures and appraisal conclusions, it lacks scientific and reasonable judgment, let alone a completely objective standard. In this way, judicial appraisal requires a series of re-appraisal operations. This is also not conducive to the unified management of Chinese judicial appraisal.

\subsection{Incomplete Information Management System for Judicial Authentication Agencies and Appraisers}

Regarding the requirements of a unified judicial authentication management model, the information of judicial authentication institutions and judicial authenticators needs to be fully registered, which is also the fundamental requirement for the unified management of the entire authentication object. However, the management model implemented at this stage does not carry out filing and registration of information on judicial institutions and appraisal personnel. As a result, the information management system cannot be perfected, and subsequent appraisal institutions and appraisers' qualification examinations cannot be carried out in an orderly manner, and false appraisals may even occur. Besides, in the implementation of actual appraisal work, there is a phenomenon of falsification in actual security and true participation. Due to the incomplete information of the judicial appraiser, the appraiser finally urged the appraiser to misreport the number and quality of the cases he appraised, which affected the cases and even the sex. This will also cause law enforcement officers to neither form a clear registration record for the appraiser's information, nor to reflect the appraiser's practice information. Meanwhile, this poses a big challenge for the development of unified management [2].

\subsection{Forensic Appraisal Management and Supervision Are A Mere Formality}

The traditional forensic appraisal management and execution links are quite out of touch, especially in the forensic appraisal commission and cross-examination, and the lack of effective linkage and supervision mechanism. This has led to the lack of transparency in forensic appraisal, the problems of illegal and illegal appraisal are very obvious, and law enforcement personnel are even unable to carry out effective follow-up management of the number and quality of appraisal cases. However, law enforcement personnel cannot effectively supervise the quality and integrity supervision system of judicial authentication institutions. Many appraisers, due to their personal interests, arbitrarily leak case information and inquire inside information, which affects the fairness and impartiality of the appraisal industry. When the appraisal information cannot be disclosed, the parties cannot clearly understand the specific case process, and the client cannot understand the appraisal institution and the appraisal's practice, which will greatly affect the client's right to know. In the entire case circulation, the setting of supervision links is not perfect, which leads to the inability to supervise the circulation process of authentication materials and to formulate a reasonable management system for authentication materials. This will increase the probability of concealment of judicial expertise. Otherwise, the phenomenon of material loss also occurs from time to time, which leads to great damage to the legal rights of the client and prevents the judicial appraisal from showing its authority.

Furthermore, various supervision agencies have some shortcomings in the management of judicial authentication, and local supervision agencies cannot truly perform their supervision duties. In the meantime, the administrative supervision agency still lacks the ability to supervise and manage judicial authentication, and the managers do not have knowledge of judicial authentication, which cannot guarantee the perfection of judicial authentication. The management of forensic appraisal is often limited in form, which ultimately has an impact on the intensity of forensic appraisal supervision. In this way, it is impossible to construct the corresponding appraiser's integrity level, and the design of the punishment system also has defects, which affects the authority of appraisal work. It is precisely because of the above-mentioned problems in the management of forensic appraisal that this has not only caused great challenges to the management model of forensic appraisal, but also led to the imperfect management of forensic appraisal. In general, judicial appraisal is an important link in litigation activities. However, due to the inadequacy of the management concept of forensic appraisal and the current level of litigation in my country, the effect is difficult to show. In order to better solve the above-mentioned problems, the actual judicial appraisal management model should be connected with the Chinese criminal procedure system to ensure the standardization and unified development of management. 


\section{The Main Content of Big Data TECHNOLOGY IN THE CONSTRUCTION OF "INTERNET + SMART JUDICIAL APPRAISAL"}

\subsection{Build A Case Database}

In China, judicial authentication has a long history of development. As of 2016, the number of judicial authentication institutions in China has reached 4872, and we can complete identification operations for many cases. It can be seen from the judiciary's case appraisal work in recent years that the types of cases involved in China are very complex, and the trend of diversity and diversification is constantly improving. With the gradual development of cases, various judicial institutions can accumulate a lot of information to make judicial institution appraisal more accurate and precise, which in turn creates many favorable conditions for the stable development of judicial institutions. After the appraisal agency completes the relevant appraisal tasks, it should also do the appraisal records. Both paper and electronic records should be classified and stored appropriately to provide a clear direction for the subsequent identification of similar cases [3].

\subsection{Establish Standard Library}

The results of judicial appraisal can provide a corresponding reference basis for judicial judgment. More importantly, the responsibilities of the judiciary are clear. We need to conduct a comprehensive supervision and management of the judicial appraisal team, and perform a series of inspection operations on the judicial appraisal activities to ensure that all work processes are in compliance with relevant standards and system requirements. What'smore, we will also implement comprehensive judicial construction operations in accordance with established rules and regulations and laws and regulations. This is also the fundamental prerequisite for maintaining the effectiveness of judicial expertise. It can also be seen from this that the content expansion of the standard library is an important part of ensuring the normal operation of the judicial mechanism. In this process, the most representative documents are the "Criteria for Identification of the Degree of Human Injury", "Power of Attorney for Judicial Expertise" and so on. These contents can provide pertinent references for judicial appraisers when performing their tasks. It should be noted that the state and relevant departments need to provide staged suggestions for the development of judicial appraisal departments based on actual conditions and issue corresponding standards and requirements. Especially in the application of big data platform, the country needs to integrate and publicize specific standards to strengthen the effectiveness of the standards.

\subsection{Build A Resource Center Library}

The core content of the actual big data platform construction process is the design of the resource center library. The application of big data data path can realize accurate calculation of data information. But to do this operation, certain prerequisites are required, that is, forensic appraisal itself needs to have a lot of data. Only in this way can we ensure the effective integration and calculation of data. In addition, the common types of data in the actual forensic appraisal process include physical evidence, forensic appraisal, and audiovisual materials. Relevant legal regulations indicate that in addition to evidence in the traditional sense, electronic evidence also has legal effects. This is also the fundamental reason why electronic evidence has an important position in platform construction. In the actual forensic identification big data platform construction, the staff also need to fully consider the forensic identification process issues. We should determine the most important item content among the many types of judicial appraisal and establish a database for it. This can provide a reference for the follow-up forensic appraisal work and maintain a good presentation of the forensic appraisal effect [4].

\section{Suggestions on The Specific ApPlication of Big DATA TECHNOLOgy IN "INTERNET + SMART JUDICIAL APPRAISAL"}

At this stage, Internet + judicial authentication is an inevitable trend in the development of the judicial authentication industry in the information age, which can strengthen the objective effectiveness of judicial authentication. Simultaneously, it is also the fundamental requirement for judicial authentication in the Internet age. From the perspective of the development of Internet + judicial authentication, the role of big data technology is particularly obvious. This is also the source of motivation for the development of the Internet + judicial authentication industry. To this end, in the specific big data environment, relevant judicial authentication departments and staff should do the following work.

\subsection{Pay Attention to the Collection and Sorting of Forensic Identification Data}

In the current process of forensic appraisal informatization, Internet + forensic appraisal has made great achievements, but compared with the expected construction goal of Internet + forensic appraisal, it still needs to be further improved. Up to now, the main line of information construction is website construction and information management platform construction, which basically realizes the whole process of paperless office. The application of big data technology can shift the construction of forensic appraisal informatization from the traditional form of website construction to the construction of big data analysis platform, which ensures the further improvement of the effectiveness of forensic appraisal. To this end, relevant staff must first collect and sort out judicial authentication data. The main function of big data technology is to realize massive data analysis and application, and draw conclusions from data with relatively low value density. The entire process of big data technology application should be based on the collection 
and sorting of forensic data. Only by ensuring that the types and quantities of data are sufficient can the big data technology be used. For the presentation of the content of data collection, in addition to the literature and standards, it also includes the collection of case data and electronic evidence resources. In fact, documentation and normative standards are appraisal tools in judicial appraisal, and people can understand normative standards through big data platforms. This can reduce the preparatory workload of the appraisers. The collection and sorting of relevant evidence can provide direction for subsequent appraisal agencies and improve the efficiency of judicial appraisal [5].

\subsection{Understand the Needs of Forensic Appraisal Big Data Applications}

The application of big data technology in the "Internet + smart forensic appraisal" is based on the needs of forensic appraisal informatization. In other words, we need to have a clear understanding of the informatization construction of forensic appraisal. Only in this way can the role of big data technology be revealed. First of all, we should do a good job in standardizing standard query operations. Forensic appraisal activities are carried out very professionally, and their standard requirements are relatively strict. Any violation of appraisal standards and norms may have an impact on the fairness of judicial appraisal activities. Therefore, people should ensure that big data technology can provide verifiers with accurate standard query services. Secondly, we should ensure the support of identification technology. In contrast, the professional characteristics of appraisal activities are more obvious. In appraisal, big data technology can provide perfect technical support for appraisers. Especially in the identification of electronic evidence, the role of identification cannot be ignored. Finally, we should provide corresponding data services for judicial appraisal. The application of big data technology in the "Internet + smart judicial appraisal" needs to provide data services for subsequent appraisal activities, which can reduce the possibility of related problems.

\subsection{Build A Big Data Analysis Platform for Judicial Authentication}

The construction of the entire big data analysis platform is the ultimate goal of the application of big data technology in the "Internet + smart judicial appraisal". At this stage, many judicial authentication agencies have realized the importance of big data analysis platforms, and they have started to build analysis platforms based on original data resources. The current big data analysis platform is mainly based on the independent creation of different appraisal institutions. The funding is very sufficient, and the appraisal institutions with a long history of development have absolute advantages in this regard, and the results they have achieved are more prominent. For those ordinary appraisal institutions, the actual construction and application of big data analysis platforms are still in their infancy. In contrast, the US Forensic Expertise Big Data Analysis Center is a subsidiary of the US Department of Justice. Its data resources come from the sharing of authorized authentication agencies and organizations, as well as the new data resources left by big data analysis services. These resources jointly establish the data resource accumulation content of the big data analysis platform. For example, according to statistics from the Judicial Expertise Administration of the Ministry of Justice, from 2012 to 2018 alone, the volume of judicial authentication business in China has shown an upward trend year by year. The specific situation is shown in Figure 1 [6].

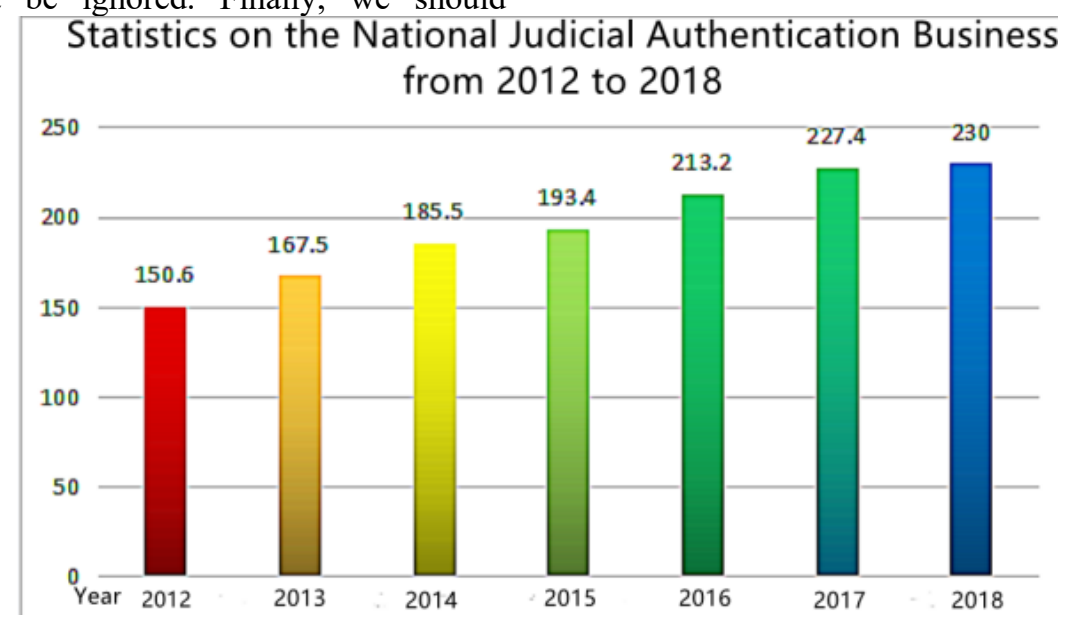

Figure 1. Statistics on the National Judicial Authentication Business from 2012 to 2018

In recent years, with the joint efforts of people's courts and judicial administrative departments in various places, as well as the application of big data technology in the "Internet + Smart Judicial Authentication", the judicial authentication business has been increasing year by year, and the judicial authentication effect has been more obvious.

\subsection{Strengthen the Network Sharing of Big Data Analysis Platform Resources}

First of all, various functional departments should act as intermediaries in the construction of the actual judicial appraisal big data analysis platform. This can ensure that 
judicial authentication agencies are based on universities or scientific research institutions, and can do joint research on big data analysis platforms, and can also clarify the advantages of big data analysis platforms based on the main characteristics of judicial authentication institutions. Secondly, when using big data analysis platforms, forensic authentication agencies should increase their emphasis on the establishment of authorization and data resource sharing systems. All judicial authentication institutions should reach cooperation with other judicial institutions to truly realize resource sharing.

\section{CONCLUSION}

To sum up, the Internet era has brought many new challenges and opportunities for judicial authentication. Relevant staff need to start from the characteristics of the Internet era to ensure the network and information development of judicial authentication and strengthen the effectiveness of judicial authentication. This is also the basis for achieving the goal of judicial expertise. Furthermore, big data has positive significance in the development of Internet + judicial authentication. People need to make full use of big data technology to clarify the role and value of judicial authentication.

\section{REFERENCES}

1. Yu Jixuan. Analysis of Big Data Technology to Reduce Deviations in the Criminal Justice System_-Based on the Background of New Coronary Pneumonia Epidemic[J]. Special Economic Zone, 2020(08):109-113.

2. Cheng Chen. Research on related issues of big data technology in the judicial field [J]. Journal of Shanxi Provincial Institute of Political Science and Law, 2020, 33(02): 106-109.

3. Ni Bin. Analysis of the application of "Internet + Wisdom Forensic Expertise" based on big data technology [J]. Digital Technology and Application, 2020, 38(02): 55-56.

4. Miao Cheng. The development status of artificial intelligence and big data technology in the judicial field[J]. Legal Exposition, 2019(19): 14-17.

5. Wu Weiguang. Building a big data technology regulatory system that combines public and private rights $[\mathrm{J}]$. Research in Network Information Law, 2019 (01): 127-156+336.

6. The data comes from the statistical analysis of the national judicial expertise published by the Judicial Expertise Administration of the Ministry of Justice in the "China Judicial Expertise" from 2012 to 2018. 